\title{
Research on Effects and Compatibility Taking of Different Sports Supplements on the Biochemical Indicators and Body Functions of Elite Walking Athletes
}

\author{
Jia Jia ${ }^{*}$ \\ Inner Mongolia Normal University, Hohhot, Inner Mongolia, China
}

\begin{abstract}
Scientific training, elimination of fatigue, and reasonable nutrition are three important parts of successful training. The fatigue recovery and reasonable nutrition are especially of great significance to track and field endurance project. Our study proved that scientific nutritional intervention could improve performance of walking athletes. We selected 12 male and 12 female athletes, who are from the Chinese national walking team, to give the nutrition intervention of a kind of composite sports supplements for 9 weeks. The levels of serum testosterone (T), blood urea (BU), serum creative phosphokinase (CK) and some other indicators were tested during five training stages. we found that taking composite sports supplements can increase the $\mathrm{T}$ levels of male and female walking athletes, and promote the body protein synthesis and accelerate rapid recovery, reduce the levels of serum CK and BU abnormalities after the intensity training, and ensure the smooth completion of the training and a normal competitive level. The composite sports supplements can improve the biochemical indicators and improve the level of physical function.
\end{abstract}

Keywords: Athlete, Biochemical indicators, Blood testosterone (T), Blood urea nitrogen (BUN), Bodily function, Hemoglobin (Hob), Lycopene, Red Jing Tian, Sports supplements, Training level, Walking.

\section{INTRODUCTION}

The nutritional supplements of general athletes are mainly considered to contain protein, fat, sugar, water, in-organic salt, vitamin and other nutrilites [1]. The under load of athletes body is serious, which may cause high-level endurance athletes a variety of exercise-induced diseases such as excessive fatigue in the case of insufficient nutritional supplements intake. According to the theory of biochemistry analysis, home iron, L-carnation, glutamine, lycopene thistle sapiens and Chinghai Jing Xian Ling are common compatible ingredients. Studies have shown that the circulating iron has good effects on promoting bone marrow hematopoietic, treating hemolytic and uncontrollable hemorrhagic anemia, and regulating iron enzyme activity. L-carnation is useful in fat-burning, which improves sports power ratio; it can also remove excess lactic acid and delay fatigue. Glutamine is a crucial amino acid in preventing muscle protein decomposition, and promoting muscle growth. It also can stimulate the secretion of growth hormone, insulin and testosterone; reduce lactic acid accumulation, which is caused by the movement of the exercise capacity and fatigue. Rheidol rose plays a key role in regulating the immune function of human body, delaying the production of sports fatigue, reducing blood urea nitrogen levels after intensive training, and promoting the recovery of body function $[2,3]$. This study selected 24 outstanding athletes from national race team as the research object, and adopted composite sports supplements,

*Address correspondence to this author at the Inner Mongolia Normal University, Hohhot, Inner Mongolia, China; Tel: 18986139113; E-mail: hunter2011@foxmail.com aiming at improving athletes body function and athletic ability.

This research is supposed to test a kind of composite sports in different training phase to determine the related biochemical indicators. It aims to race nutrition intervention and provide experimental basis for scientific training and improve performance of walking athlete's.

\section{OBJECT AND METHODS OF EXPERIMENT}

The objects of study are 24 race walking athletes consisting of 12 males and 12 females

\subsection{Experimental Supplements}

Hammer TM home iron, L-carnation capsule, 100\% health bit pancreatic phthalein amine capsules, health bit of lycopene, Chinghai JingXianLing. The above medicines are bought from Beijing sports nutrition health Bit Company.

\subsection{Training Plan}

(1) The first stage: the basic preparation period (The $1^{\text {st }}$ week). Giving priority to strength training, the aim of this stage is to achieve the breakthrough of strength and the coordination of the body.

(2) The second stage: the improving ability period $\left(2^{\text {nd }}\right.$ to $4^{\text {th }}$ week, 3 weeks in total). Paying more attention to special endurance training, especially on overcoming the difficulties after long process of physical deficiency and the lack of ability. 
(3) The third stage: the adjustment period (The $5^{\text {th }}$ week). With a relatively high intensity but less amount of exercise, intermittent training is designed to maintain the special ability of body to decline.

(4) The fourth stage: the consolidating and enhancing ability period ( $6^{\text {th }}$ to $8^{\text {th }}$ week, 3 weeks in total). The combination of interval training and speed training improves special ability in this personalized training.

(5) The fifth stage: the pre-match preparations period (The $9^{\text {th }}$ week) some positive adjustments are carried out according to the recent training situation to meet the requirements of the game. Getting sufficient physical strength exercise with low load to avoid fatigue caused by training $[4,5]$.

\subsection{Results of Experiments}

Composite sports supplements take effect in morning pulse change walker. As Fig. (1) shows, the morning pulses of male and female walking athletes fluctuate along with the amount of exercise during the whole training period, and two peaks appeared at the $4^{\text {th }}$ and the $8^{\text {th }}$ week. At the same time three low morning pulses appeared at the $1^{\text {st }}$, the $5^{\text {th }}$ and the $9^{\text {th }}$ week. It has been noticed that it reached to the lowest point in the $9^{\text {th }}$ week.

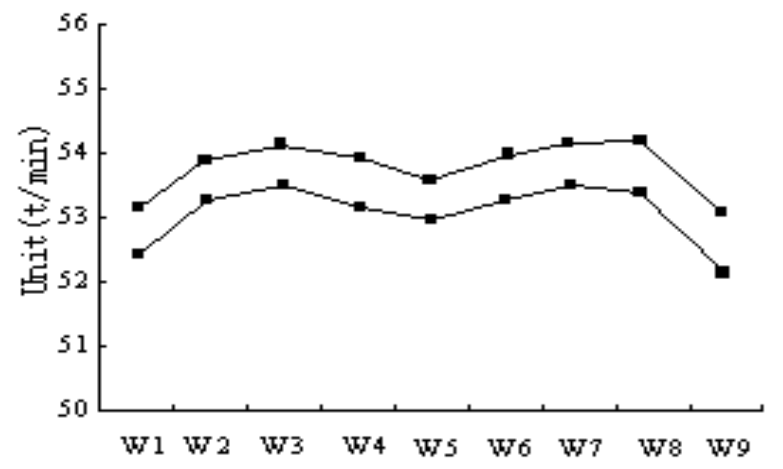

Fig. (1). Mean values of male and female athletes' morning pulse in different training phases.

It can be seen from Table 1 that in the second stage (the ability rising period, the $2^{\text {nd }}-4^{\text {th }}$ week) and the fourth stage (the ability consolidating and rising period, the $6^{\text {th }}$ to the $8^{\text {th }}$ week), the athletes' morning pulses appeared in two peaks. The athletes' morning pulses in both the second and the fourth stages were significantly higher than that in the first stage $(\mathrm{P}<0.05)$, we suspect it is because athletes have not adapted to the exercise intensity change. The morning pulses values obviously decreased in the third phase (phase adjustment, $5^{\text {th }}$ week) and the fifth stage (pre-match preparations period, $9^{\text {th }}$ week) compared with the second phase $(\mathrm{P}<0.05)$. Both the male and female athletes have the lowest morning pulse value in the fifth stage $(\mathrm{P}<0.01)$.

\section{AFFECTS OF COMPATIBILITY OF DIFFERENT SPORTS SUPPLEMENTS ON DIASTOLIC BLOOD PRESSURE CHANGES OF RACE WALKERS}

To determine the effect of composite sports supplements on the average diastolic blood pressure of walking athletes, we measured the walker average diastolic blood pressure of male and female athletes in the early morning during the whole training period. As Fig. (2) shows the athletes' diastolic pressures change along with the amount of exercise. Two peaks appeared in the $4^{\text {th }}$ and the $8^{\text {th }}$ week, which dropped down in the $1^{\text {st }}$, the $5^{\text {th }}$ and the $9^{\text {th }}$ week, the diastolic pressures demonstrate similar changing trend with the morning pulse, which is the values in the $9^{\text {th }}$ week reaching to the lowest point in the whole training period $[6,7]$.

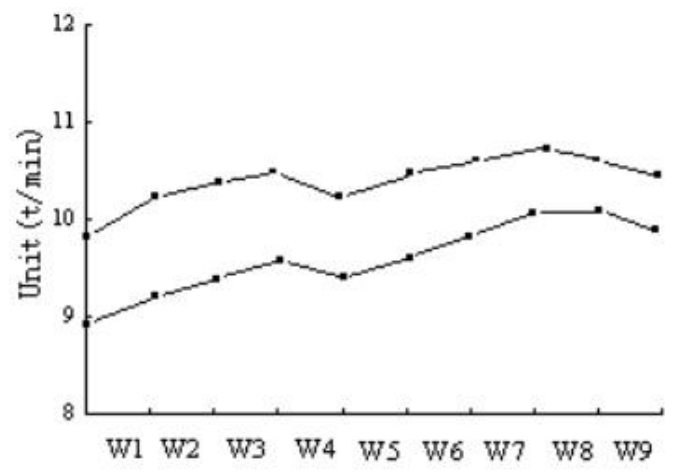

Fig. (2). Mean values of male and female athletes' diastolic pressure in different training weeks.

As it can be seen from Table 2, the athletes' average morning diastolic blood pressure values change along with the physiological load and intensity of exercises. The values in the second stage (the improving ability period) and the fourth stage (the ability consolidating and rising period) were significantly higher than that in the first stage, $(\mathrm{P}<0.05)$. We therefore, proposed that high intensity exercises lead to the high morning diastolic blood pressure. In the third stage (the adjustment period) and the fifth stage (the pre-match preparation), it can also be observed that the morning diastolic blood pressure showed a marked decline, compared to the second phase $(\mathrm{P}<0.05)$. And the early diastolic blood pressure of both male and female walking athletes in the fifth stage is significantly higher than that of the other four stages $(\mathrm{P}<0.01)$.

We also tested the routine blood indexes of athletes during the training phase. As it can be seen from Table 3, the average amounts of HCT (blood red blood cell volume), Hob (hemoglobin), $\mathrm{MCH}$ (the average amount of red blood cell hemoglobin), RBC (red blood cell count) and MCHC of male athletes (RBC)in the second stage significantly reduced $(\mathrm{P}<0.05)$. The values of RBC, MCV, Hob, $\mathrm{MCH}$ and $\mathrm{MCHC}$ of male athletes increased significantly in the third stage $(\mathrm{P}<0.05)$. The amounts of RBC, MCV and RDW (red blood cell distribution width) of male athletes increased apparently in the fourth stage compared to the first stage $(\mathrm{P}<0.05)$, but the values of Hob in male athletes decreased $(\mathrm{P}<0.05)$, and values of $\mathrm{MCH}$ and $\mathrm{MCHC}$ also declined $(\mathrm{P}<0.01)$.

\section{EFFECT OF DIFFERENT SPORTS SUPPLEMENTS COMPATIBILITY ON BLOOD BIOCHEMICAL IN- DICATORS IN WALKER}

To further study the influences of composite sports supplements on blood testosterone levels of walking athletes, we tested the testosterone levels of athletes in five stages. We found that the testosterone levels in both male and female athletes in the first, the third and the fifth stages increased 
Table 1. Mean values of male and female athletes' morning pulse in different training phrases.

\begin{tabular}{|c|c|c|c|c|c|}
\hline Sex & $\begin{array}{c}\text { First stage } \\
\text { (times/min) }\end{array}$ & $\begin{array}{c}\text { Second stage } \\
\text { (times/min) }\end{array}$ & $\begin{array}{c}\text { Third stage } \\
\text { (times/min) }\end{array}$ & $\begin{array}{c}\text { Forth stage } \\
\text { (times/min) }\end{array}$ & $\begin{array}{c}\text { Fifth stage } \\
\text { (times/min) }\end{array}$ \\
\hline \hline Man & $52.30 \pm 4.58$ & $53.94 \pm 4.80$ & $52.77 \pm 3.93$ & $54.39 \pm 4.74$ & $51.89 \pm 4.82$ \\
\hline Woman & $53.29 \pm 4.18$ & $54.33 \pm 3.51$ & $53.64 \pm 3.83$ & $54.69 \pm 3.94$ & $53.07 \pm 4.16$ \\
\hline
\end{tabular}

Table 2. Mean values of male and female athletes' diastolic pressure in different training phrases.

\begin{tabular}{|c|c|c|c|c|c|}
\hline Sex & $\begin{array}{c}\text { First stage } \\
\text { (times/min) }\end{array}$ & $\begin{array}{c}\text { Second stage } \\
\text { (times/min) }\end{array}$ & $\begin{array}{c}\text { Third stage } \\
\text { (times/min) }\end{array}$ & $\begin{array}{c}\text { Forth stage } \\
\text { (times/min) }\end{array}$ & $\begin{array}{c}\text { Fifth stage } \\
\text { (times/min) }\end{array}$ \\
\hline \hline Man & $52.30 \pm 4.58$ & $53.94 \pm 4.80$ & $52.77 \pm 3.93$ & $54.39 \pm 4.74$ & $51.89 \pm 4.82$ \\
\hline Woman & $53.29 \pm 4.18$ & $54.33 \pm 3.51$ & $53.64 \pm 3.83$ & $54.69 \pm 3.94$ & $53.07 \pm 4.16$ \\
\hline
\end{tabular}

Table 3. Mean values of male athletes' RBC, $\mathrm{Hb}$ and other parameters in all training phrases.

\begin{tabular}{|c|c|c|c|c|c|}
\hline Index & First stage (kpa) & $\begin{array}{c}\text { Second stage } \\
\text { (kpa) }\end{array}$ & Third stage (kpa) & Forth stage (kpa) & Fifth stage (kpa) \\
\hline \hline $\mathrm{RBC}(\mathrm{x} 109 / \mathrm{L})$ & $5.19 \pm 0.43$ & $4.87 \pm 0.52$ & $5.15 \pm 0.46$ & $4.78 \pm 0.57$ & $5.15 \pm 0.52$ \\
\hline $\mathrm{HCT}(\mathrm{L} / \mathrm{Lx} 102)$ & $45.38 \pm 1.12$ & $43.13 \pm 1.58$ & $4499 \pm 1.25$ & $43.42 \pm 1.51$ & $45.67 \pm 1.54$ \\
\hline $\mathrm{MCV}(\mathrm{fL})$ & $89.69 \pm 3.42$ & $92.68 \pm 3.85$ & $90.90 \pm 3.68$ & $93.88 \pm 1.44$ & $91.30 \pm 4.52$ \\
\hline $\mathrm{RDW}(\mathrm{fL})$ & $13.04 \pm 0.52$ & $14.26 \pm 0.69$ & $13.67 \pm 0.55$ & $14.57 \pm 0.75$ & $12.50 \pm 056$ \\
\hline $\mathrm{Hb}(\mathrm{g} / \mathrm{L})$ & $139.20 \pm 9.95$ & $129.62 \pm 10.20$ & $141.56 \pm 8.14$ & $131.56 \pm 10.24$ & $148.63 \pm 12.56$ \\
\hline $\mathrm{MCH}(\mathrm{pg})$ & $27.64 \pm 1.80$ & $24.85 \pm 2.06$ & $28.77 \pm 2.65$ & $25.75 \pm 2.65$ & $30.46 \pm 2.41$ \\
\hline $\mathrm{MCHC}(\mathrm{g} / \mathrm{L})$ & $308.93 \pm 9.21$ & $288.15 \pm 10.36$ & $293.31 \pm 12.56$ & $293.31 \pm 12.56$ & $328.93 \pm 13.92$ \\
\hline
\end{tabular}

Table 4. Changes of serum testosterone content in male and female athletes at various training phrases.

\begin{tabular}{|c|c|c|c|c|c|}
\hline Sex & First stage (kpa) & $\begin{array}{c}\text { Second stage } \\
\text { (kpa) }\end{array}$ & Third stage (kpa) & Forth stage (kpa) & Fifth stage (kpa) \\
\hline \hline Man & $564.39 \pm 119.32$ & $524.35 \pm 128.77$ & $575.19 \pm 128.54$ & $538.89 \pm 1.72$ & $605.57 \pm 216.30$ \\
\hline Woman & $32.53 \pm 8.52$ & $27.55 \pm 15.88$ & $35.22 \pm 9.59$ & $29.16 \pm 1.65$ & $36.85 \pm 14.36$ \\
\hline
\end{tabular}

Table 5. Changes of blood urea content in male and female athletes at various training phases.

\begin{tabular}{|c|c|c|c|c|c|}
\hline Sex & First stage (kpa) & $\begin{array}{c}\text { Second stage } \\
(\mathbf{k p a})\end{array}$ & Third stage (kpa) & Forth stage (kpa) & Fifth stage (kpa) \\
\hline \hline Man & $12.30 \pm 2.31$ & $16.54 \pm 3.25$ & $13.74 \pm 3.25$ & $16.80 \pm 2.55$ & $12.85 \pm 3.46$ \\
\hline Woman & $10.62 \pm 2.82$ & $15.69 \pm 3.62$ & $12.68 \pm 3.40$ & $15.92 \pm 3.35$ & $11.69 \pm 3 / 92$ \\
\hline
\end{tabular}

significantly $(\mathrm{P}<0.05)$. It is also noticed that the lowest values of testosterone levels appeared in the second stage but the highest ones are achieved in the fifth stage $(\mathrm{P}<0.05)$.

\section{INFLUENCE OF BLOOD UREA LEVELS ON RACE WALKING ATHLETES}

Blood urea is a biochemical indicator which can reflect the functional status and diet can also be used to measure the size of the training load. We also measured the blood urea level of athletes during five stages. It can be seen from Table 5 that the blood urea levels of male and female athletes in five training stages varied in different changing modes of serum testosterone. On the contrary, the blood urea levels in the first, the third and the fifth stage are lower than that in the second and the fourth stage $(\mathrm{P}<0.05)$. 


\section{CONCLUSION}

A series of experiments test the function of composite sports supplements, which may lead us to draw some conclusions. In the first place, these composite sports supplements can accelerate the morning pulse recovery level in both male and female walking athletes during the high strength training, suggesting that the ability of the athlete's heart rate was improved, which is an advantage in the functional recovery after the exercise. We can use composite sports supplements to adjust the blood pressure levels and improve myocardial contraction of male and female walking athletes in the intense strength training period. It makes easy to adapt quickly to the change of the exercise load. Secondly, since composite sports supplements can prevent the oxidative damage and the aging process of red blood cells, it protects red blood cells structural integrity as well. Finally, composite sports supplements can be used to decrease the blood urea level increased by abnormal load exercises and reduce the fatigue level of athletes, which play a vital role in ensuring the smooth completion of the training mission and normal play of the competitive level.

\section{CONFLICT OF INTEREST}

The author confirms that this article content has no conflict of interest.

\section{ACKNOWLEDGEMENTS}

This work is supported by the Key Project of Guangxi Social Sciences, China (No. gxsk201424), the Education
Science fund of the Education Department of Guangxi, China (No. 2014JGA268), and Guangxi Office for Education Sciences Planning, China (No. 2013C108).

\section{REFERENCES}

[1] C. Guowen and M. Shaohua, "Endurance events of track and field sports nutrition deployment problem study", J. Yunnan Normal Univ.: Natural Sci. Ed., vol. 25, no. 1, pp. 68-72, 2005.

[2] F. Lianshi and F. L. Kaigang, Athletes Function Evaluation of Physiological and Biochemical Indexes Commonly Used Testing Method and Application. Beijing: People's Sport Publishing House, 2002.

[3] H. Hengyang and F. Studio, "Sakhalin rhodiola anti-fatigue function mechanism of the rat experimental study", J. Ch. Med. Univ., vol. 27, no. 2, pp. 123-125, 1998.

[4] N. Hongu, "Carnitine and choline supplementation with exercise alter carnation profiles biochemical markers of fat metabolism and serum lepton concentration in healthy women", J. Nutrit., vol. 133, no. 1, pp. 8489-8492, 2003.

[5] X. Zhengying and L. Sequin, "Thistle extracts glycogen, blood testosterone of trained rats and the influence of exercise capacity", J. Sports Sci., vol. 24, no. 8, pp. 3237-3261, 2004.

[6] Y. Chula and L. Ziti, "Lycopene research status quo of health care function", J. Zhejiang Univ.: Med. Sci. Ed., vol. 31, no. 2, pp. 139$142,2002$.

[7] Z. Hui, Z. Wei and W. Jiachun, "The compound rhodiola affect the metabolism of mice under different motion load", J. Naval Med., vol. 21, no. 1, pp. 29-31, 2000. 